\title{
Effects of Cardioplegia Induced by a Young's Solution (YNG Solution) on the Blood-Perfused Canine Papillary Muscle Preparation
}

\author{
Hiroshi Satoh, Ph.D., Kazuhiro Ohkubo, Kenichi Suzuki, \\ Yumi Katano, Ph.D., Takeshi Otoris, M.D., Ph.D., \\ Tomie Kawada, B.S., * Seiichiro Yoshida, Ph.D., and \\ Shoichi ImaI, M.D., Ph.D.**
}

\section{Summary}

Experiments were carried out in the blood-perfused canine papillary muscle preparation to evaluate the protective effect of a cardioplegic solution, Young's solution (YNG solution), on the myocardial function. Both in spontaneously contracting preparations and in electrically paced $(2 \mathrm{~Hz})$ preparations, the time to the cardiac arrest and the time to the maximum blood flow were found to be significantly shorter when the cardiac arrest was induced with cardioplegic solutions than when it was induced with the cold modified Krebs-Ringer's solution (cold cardioplegia). The maximum blood flow of the paced preparation tended to be greater with cardioplegic solutions. The time to resumption of regular contractions was significantly shorter with YNG solution as compared with cold cardioplegia. The developed tension and the blood flow at the time of resumption of the regular contractions tended to approach the control value more quickly with YNG solution, as compared with other cardioplegic solutions and cold cardioplegia. It is concluded that YNG solution represents an optimal cardioplegic solution.

\section{Additional Indexing Words:}

Automaticity Contractility Tension Blood flow Beating rate Oxygen consumption

7 HE selection of myocardial protection methods for open heart surgery

From the Department of Pharmacology, Yamagata University School of Medicine, Yamagata 990-23, Japan.

* Research Laboratorics, Ohta Pharmaceutical Co., Ltd., Saitama.

** Department of Pharmacology, Niigata University School of Medicine, Niigata.

Received for publication December 25, 1982.

Manuscript revised May 23, 1983. 
heart disease has increased. In contrast to surgical operations conducted under intermittent perfusion with the blood, operations under conditions of metabolic inhibition with a cardioplegic solution are advantageous in that no blood is present in the area of surgery and the heart muscle is in a relatively relaxed state. Furthermore, the cardioplegia protects the myocardial muscle from deterioration in even lengthy operations. In $1955 \mathrm{Lam}^{\mathrm{C}} \mathrm{al}^{11}$ and Melrose $\mathrm{et}^{\mathrm{a} \mathrm{l}^{2)}}$ used a high potassium cardioplegic solution. Later, Young et $\mathrm{al}^{3)}$ introduced a mixture of potassium, magnesium and neostigmine, termed Young's solution. The lower potassium concentration of Young's solution resulted in a quicker recovery of the cardiac function after operation. Another method of myocardial protection, hypothermia, was also introduced in the late 1950's. Shumway's original method ${ }^{4)}$ consisted in local cooling, while perfusion with a cold solution was adopted by Mundth et al,5) Tyers et $\mathrm{a}^{\left({ }^{6}\right)}$ and Stemmer et al. ${ }^{7)}$ Recently, Wada et al ${ }^{87}$ combined the two methods and have obtained excellent myocardial protection during operation. Their procedure involved perfusion with cold Young's solution without neostigmine. The present paper evaluates the protective effect of Young's solution (YNG solution) upon the myocardial function. Experiments were performed with blood-perfused papillary muscle preparations from the canine right ventricle and the effects on the cardiac function of YNG solution were compared with those of cardioplegic solutions of different ionic compositions.

\section{Materials and Methods}

Papillary muscle preparations of the canine right ventricle were perfused with blood from a support dog following the method of Endoh et al.9) Mongrel dogs weighing 7 to $11 \mathrm{Kg}$ were anesthetized with thiopental $(25 \mathrm{mg} / \mathrm{Kg}$ i.v.). Ten to $15 \mathrm{~min}$ after administration of sodium heparin $(500 \mathrm{U} / \mathrm{Kg}$ i.v. $)$, the animal was exsanguinated. The heart was excised and immediately plunged into modified Krebs-Ringer's solution precooled to a temperature of 5 to $10^{\circ} \mathrm{C}$ and equilibrated with a gas mixture of $95 \% \mathrm{O}_{2}+5 \% \mathrm{CO}_{2}$. The modified Krebs-Ringer's solution was of the following composition: $\mathrm{NaCl}$, $127.2 ; \mathrm{KCl}, 4.7 ; \mathrm{NaHCO}_{3}, 24.9 ; \mathrm{KH}_{2} \mathrm{PO}_{4}, 1.2 ; \mathrm{CaCl}_{2}, 2.5$; and glucose, $5.5 \mathrm{mM}$. The right ventricular free wall was removed. The anterior septal artery was dissected free from the underlying tissue and a cannula was inserted into its origin. The papillary muscle was mounted on an acrylite board equipped with stimulus electrodes as shown in Fig. 2. The tendinous end of the papillary muscle was connected to a strain gauge transducer (Nihon Kohden SB-1T) with a silk thread and was stretched to a tension of about $0.5 \mathrm{Gm}$. The perfusion of the papillary muscle with the blood from the femo- 
ral artery of a donor dog was started with the aid of a rotary pump (ColeParmer Masterflex). A starling pneumatic resistance was placed in parallel with the perfusion system to keep the perfusion pressure at $100 \mathrm{mmHg}$. The venous blood from the papillary muscle and the excess blood passing through the pneumatic resistance were collected together in a blood reservoir and returned to the donor through the femoral vein. The tension development was recorded on an ink-writing oscillograph via a carrier amplifier (Nihon Kohden PR-5). The rate of contraction was recorded through a cardiotachometer (Nihon Kohden RT-5) triggered by the pulse waves of the tension development. A cannulating type probe (Nihon Kohden FF-010T) of a rectangular pulse electromagnetic blood flowmeter (Nihon Kohden MFV 110) was placed near the anterior septal artery to measure the blood flow. Donor mongrel dogs, weighing 10 to $15 \mathrm{Kg}$, were anesthetized with morphine $(1.5 \mathrm{mg} / \mathrm{Kg}$ s.c.), $\alpha$-chloralose $(45 \mathrm{mg} / \mathrm{Kg}$ i.v.) and urethane $(450 \mathrm{mg} / \mathrm{Kg}$ i.v.). The systemic blood pressure of the donor was measured from the femoral artery with a pressure transducer coupled to a carrier amplifier (Nihon Kohden RP-5). Alpha-chloralose ( $5 \mathrm{mg} / \mathrm{Kg} / \mathrm{h}$ i.v.), urethane $(50 \mathrm{mg} / \mathrm{Kg} / \mathrm{h}$ i.v.) and sodium heparin $(200 \mathrm{U} / \mathrm{Kg} / \mathrm{h}$ i.v. $)$ were infused continuously into the femoral vein to keep the systemic blood pressure constant during the experiment. The respiration of the donor was regulated with the aid of a blood gas analyzer (IL meter) to maintain the blood $\mathrm{pH}$ at 7.35 to $7.40, \mathrm{PaO}_{2}$ at 90 to $100 \mathrm{mmHg}$ and $\mathrm{PaCO}_{2}$ at 35 to $45 \mathrm{mmHg}$. During the experiments, the papillary muscle preparations were either stimulated at $2 \mathrm{~Hz}$ or were left to contract spontancously. The stimulation of the muscle was conducted via silver electrodes

\section{Protocol}

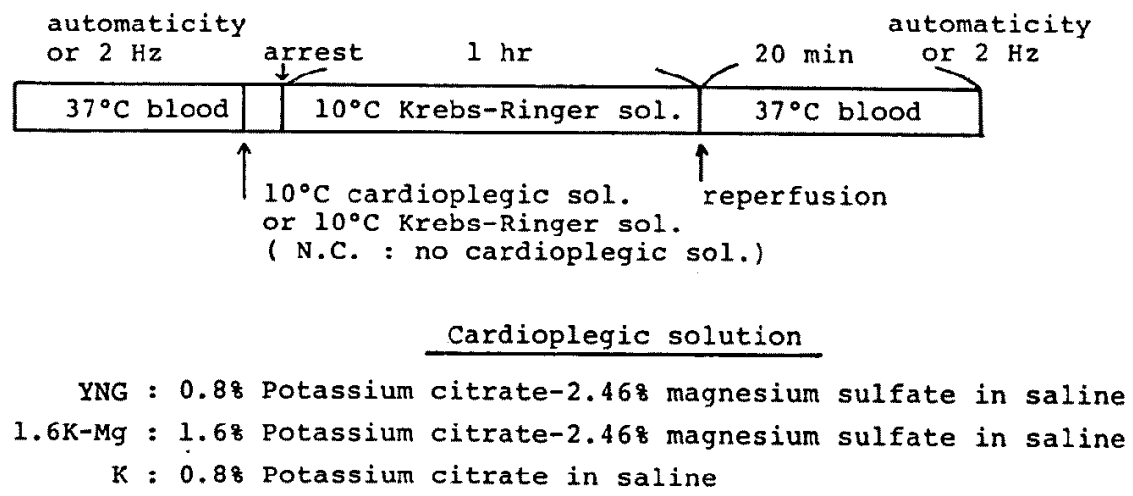

Fig. 1. Protocol of the experiments with a blood-perfused canine papillary muscle preparation. 


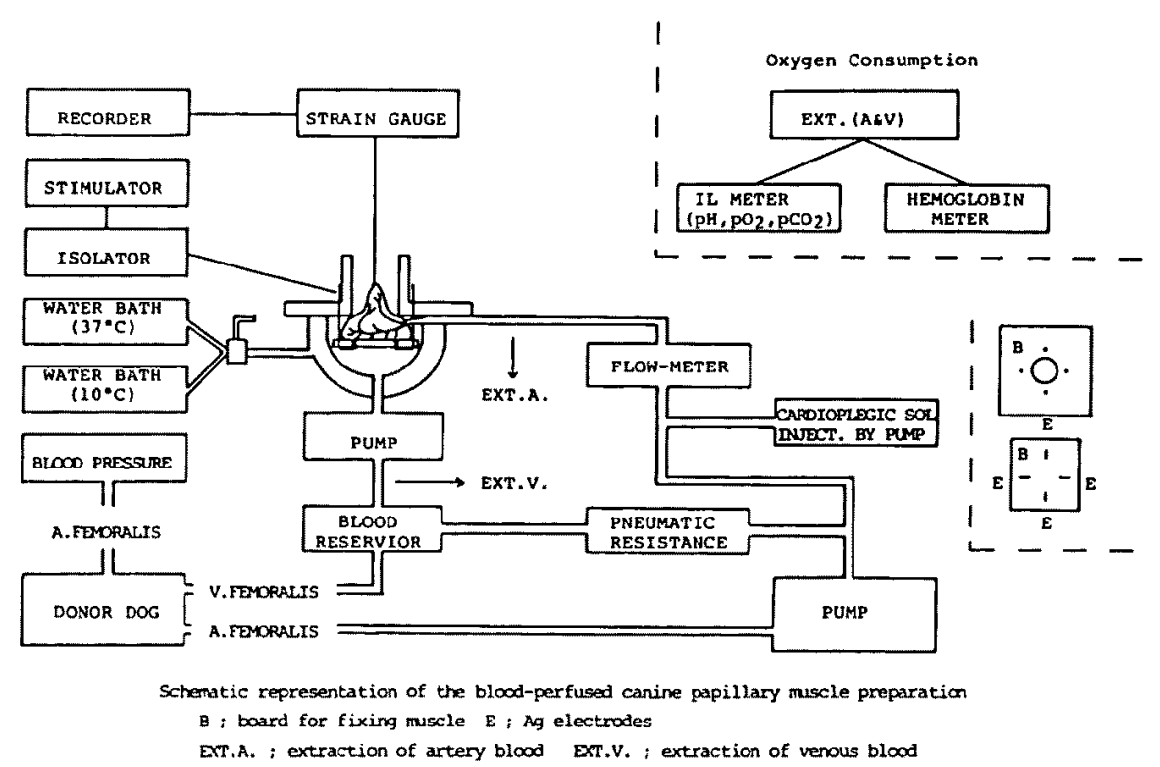

Fig. 2. Schematic representation of the blood-perfused canine papillary muscle preparation.

using rectangular pulses of $1 \mathrm{msec}$ duration at $2 \mathrm{~Hz}$ (IV) with an electronic stimulator (Nihon Kohden MSE-40) coupled with an isolator (Nihon Koden MSE-JM). The composition of cardioplegic solutions and the protocol of the experiments were shown in Fig. 1. After an equilibration period, the perfusate was changed from the blood to a cardioplegic solution at $10^{\circ} \mathrm{C}$ and the time to the cardiac arrest and the blood inflow at the time to cardiac arrest was recorded. Then the preparation was perfused for 1 hour with modified Krebs-Ringer's solution at $10^{\circ} \mathrm{C}$, which kept the preparation under conditions of arrest. In another group of preparations, cardiac arrest was induced with modified Krebs-Ringer's solution of $10^{\circ} \mathrm{C}$. The preparation was similarly perfused for 1 hour under conditions of arrest. After 1 hour of perfusion, the perfusion solution was changed to blood and the time to resumption of the contractions, the time to resumption of the regular contractions, the developed tension, the beating rate and the blood inflow were recorded. Blood samples were withdrawn before and after the papillary muscle to determine the oxygen consumption of the papillary muscle. The $\mathrm{pH}, \mathrm{PaO}_{2}$ and $\mathrm{PaCO}_{2}$ were measured using a blood gas analyzer. The concentration of hemoglobin was determined using a hemoglobinometer, and the oxygen consumption $\left(\mathrm{O}_{2} \mathrm{G}, \mathrm{ml} / \mathrm{min} / 100 \mathrm{Gm}\right)$ was calculated using the following equation, where $\mathrm{A}(\%)$ represents the oxygen saturation of the arterial blood, $\mathrm{V}(\%)$ the oxygen saturation of the venous blood, $\mathrm{Hb}$ the hemoglobin and $\mathrm{BF}$ the blood flow. 


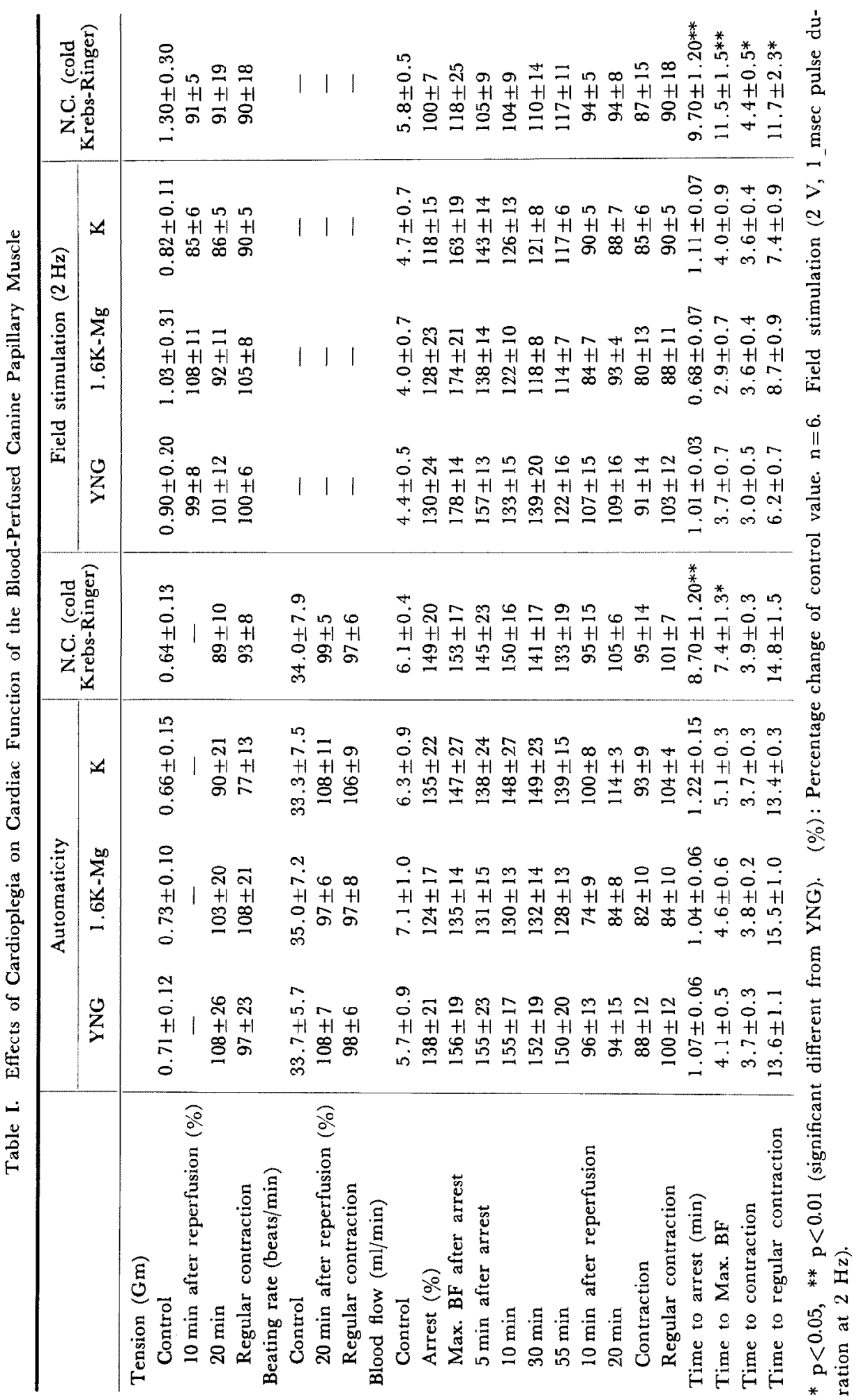




$$
\mathrm{O}_{2} \mathrm{C}=\frac{(\mathrm{A}(\%)-\mathrm{V}(\%)) \times \mathrm{Hb}(\mathrm{Gm} / \mathrm{dl}) \times \mathrm{BF}(\mathrm{ml} / \mathrm{min}) \times 0.0134}{\text { heart weight }(\mathrm{Gm})}
$$

\section{RESULTS}

The effects of cardioplegic solutions and cold cardioplegia on the function of the blood-perfused canine papillary muscle are shown in Table I. Under conditions of automaticity, the times to cardiac arrest with YNG solution, $1.6 \% \mathrm{~K}^{+}-\mathrm{Mg}^{++}$solution and $\mathrm{K}+$ solution were $1.07 \mathrm{~min}, 1.04 \mathrm{~min}$ and $1.22 \mathrm{~min}$, respectively. The time necessary for the cardiac arrest without the cardioplegic solution, i.e. with cold modified Krebs-Ringer's solution, was $8.70 \mathrm{~min}$, which was significantly longer than those necessary with cardioplegic solutions. During pacing at $2 \mathrm{~Hz}$, the times to cardiac arrest with YNG solution, $1.6 \% \mathrm{~K}^{+-} \mathrm{Mg}^{++}$solution and $\mathrm{K}^{+}$solution were $1.01 \mathrm{~min}, 0.68$ $\mathrm{min}$ and $1.11 \mathrm{~min}$, respectively. The time necessary for cardiac arrest without cardioplegic solution was $9.70 \mathrm{~min}$, which was significantly longer than necessary with cardioplegic solutions (Fig. 3). During pacing at $2 \mathrm{~Hz}$, the time to resumption of contractions was the shortest with YNG solution $(3.0 \mathrm{~min})$. With $1.6 \% \mathrm{~K}^{+-} \mathrm{Mg}^{++}$and $\mathrm{K}^{+}$solution, the time was $3.6 \mathrm{~min}$, while it was 4.4 min with cold cardioplegia. As compared with cold cardioplegia, the time to resumption of contractions was significantly shorter with YNG solution. Under conditions of automaticity, the difference between solutions was not significant (Fig. 4).

During pacing at $2 \mathrm{~Hz}$, the time to resumption of regular contractions (6.2 min) obtained with YNG solution was the shortest. The time was 8.7 min with $1.6 \% \mathrm{~K}^{+-} \mathrm{Mg}^{++}$solution and 7.4 min with $\mathrm{K}^{+}$solution, while it was

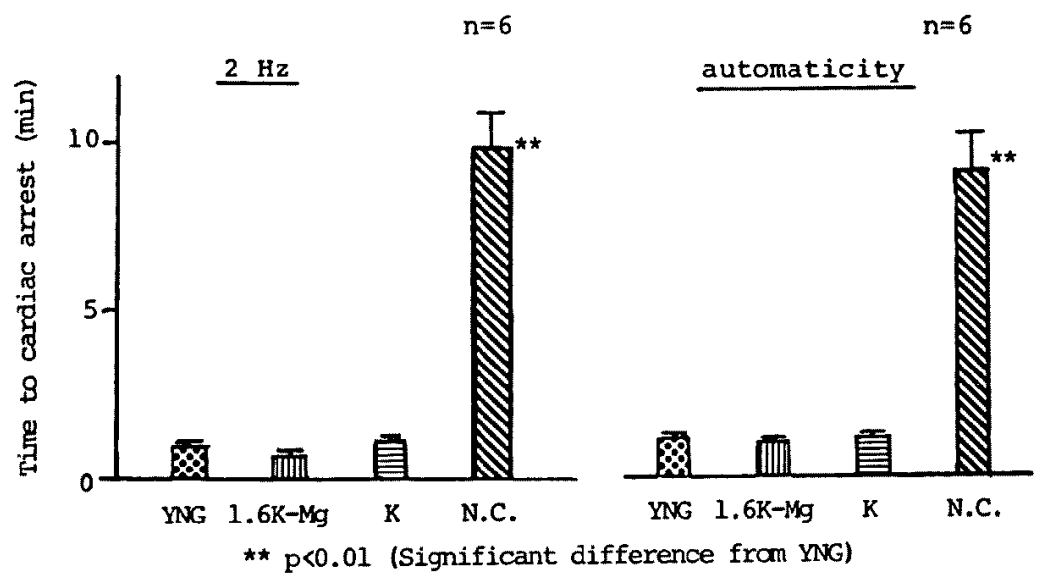

Fig. 3. Effects of cardioplegic solutions and cold cardioplegia on the time to arrest of the papillary muscle preparation. 


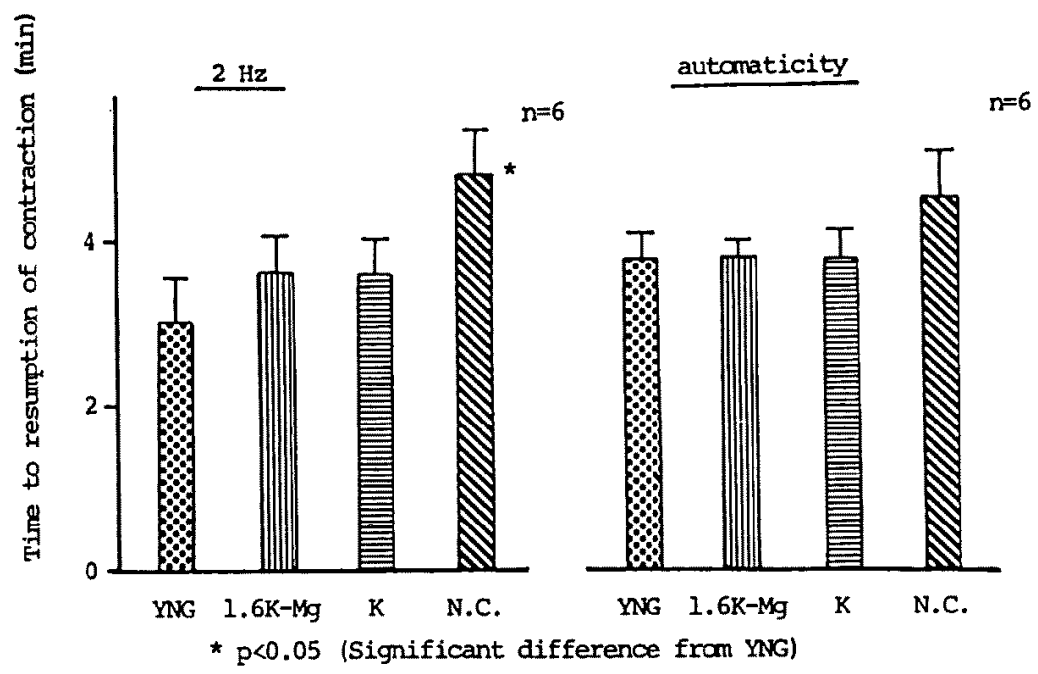

Fig. 4. Effects of cardioplegic solutions and cold cardioplegia on the time to resumption of contractions after blood reperfusion.

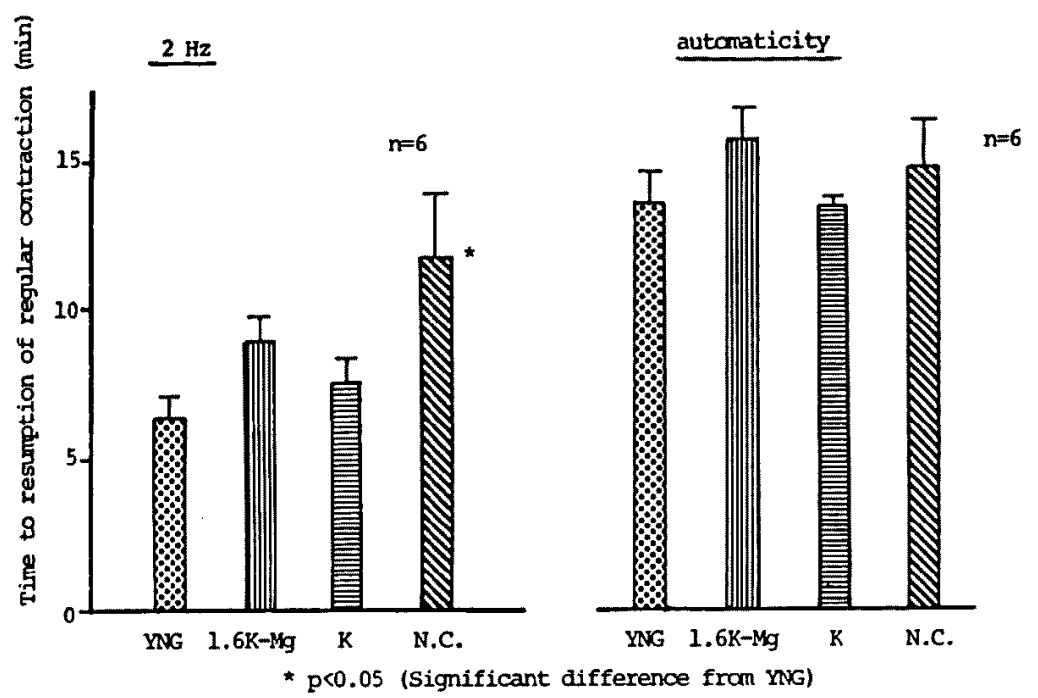

Fig. 5. Effects of cardioplegic solutions and cold cardioplegia on the time to resumption of regular contractions after blood reperfusion.

11.7 min with cold cardioplegia. As compared with cold cardioplegia, the time to resumption of regular contractions was significantly shorter with YNG solution (Fig. 5). Under both conditions of automaticity and pacing at $2 \mathrm{~Hz}$, the tension development after reperfusion with the blood of the papillary muscle which had been arrested with YNG solution or $1.6 \% \mathrm{~K}^{+-} \mathrm{Mg}^{++}$solution was almost identical with the control value before the cardiac arrest, while those of the papillary muscle arrested with $\mathrm{K}^{+}$solution or with cold 


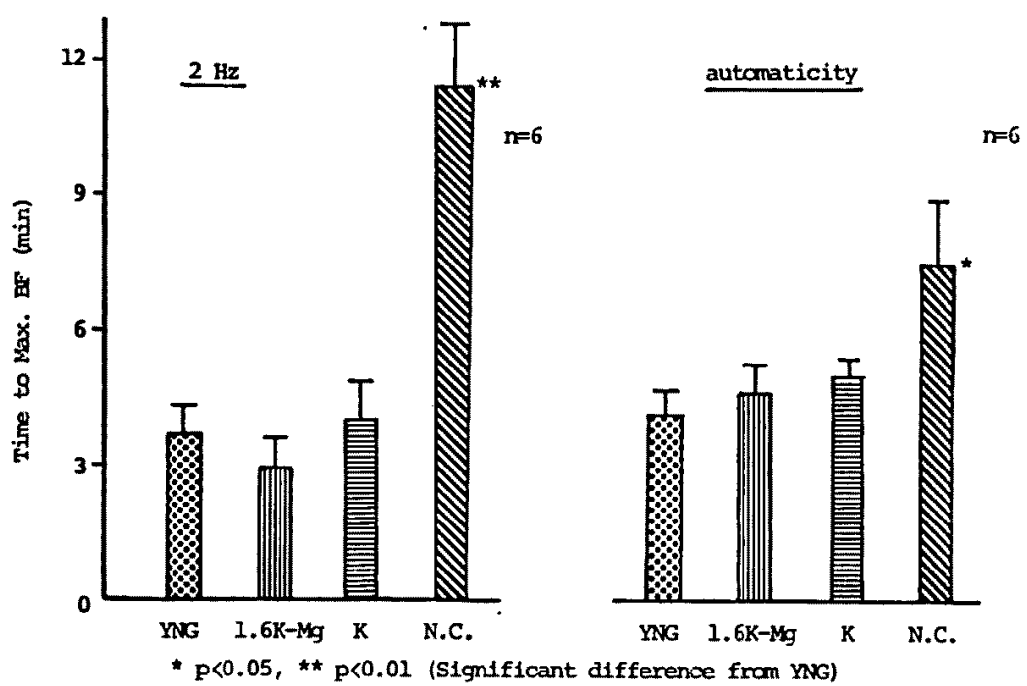

Fig. 6. Effects of cardioplegic solutions and cold cardioplegia on the time to maximum blood flow after cardiac arrest.

cardioplegia were smaller. The blood flow immediately after the cardiac arrest tended to be greater as compared with the control value before cardiac arrest. Under the condition of automaticity, the time after the cardiac arrest to the maximum blood flow of 4.1 min obtained with YNG solution was the shortest. With $1.6 \% \mathrm{~K}^{+}-\mathrm{Mg}^{++}$solution it was $4.6 \mathrm{~min}$, while they were $5.1 \mathrm{~min}$ and $7.4 \mathrm{~min}$, respectively with $\mathrm{K}^{+}$solution and with the cold cardioplegia. However, the time to the maximum blood flow was significantly shorter with cardioplegic solution than with cold cardioplegia. During pacing at $2 \mathrm{~Hz}$, the time to the maximum blood flow after the cardiac arrest (2.9 min) obtained with $1.6 \% \mathrm{~K}^{+}-\mathrm{Mg}^{++}$solution was the shortest. The values with YNG solution $\left(3.7 \mathrm{~min}\right.$ ) and $\mathrm{K}^{+}$solution $(4.0 \mathrm{~min}$ ) were also shorter than with cold cardioplegia $(11.5 \mathrm{~min})$. As compared with the cold cardioplegia, the time to maximum blood flow was significantly shorter with all cardioplegic solutions (Fig. 6). The maximum blood flow after cardiac arrest was not effected significantly by the solutions (Fig. 7). The blood flow during the perfusion with modified Krebs-Ringer's solution after the cardiac arrest under both conditions of automaticity and pacing at $2 \mathrm{~Hz}$ was higher than the control value, while the blood flow after reperfusion with the blood was lower than the control value, except for the preparations treated with YNG solution. With YNG solution, it was equal to or a little greater than the control value.

The beating rate of the papillary muscle under the condition of automaticity was 33 to 35 beats/min with all solutions. The beating rate recovered to control values $20 \mathrm{~min}$ after reperfusion with blood or at the time of resump- 

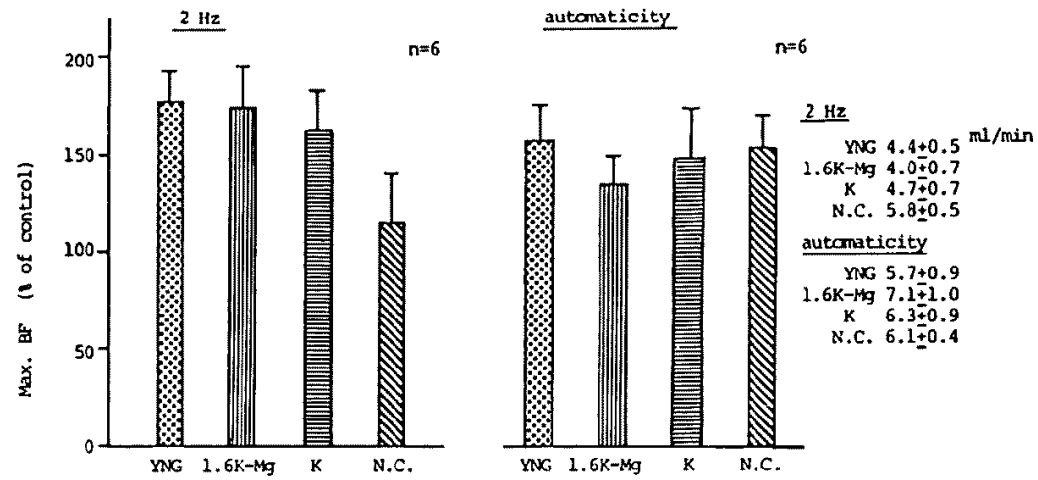

Fig. 7. Effects of cardioplegic solutions and cold cardioplegia on the maximum blood flow after cardiac arrest.

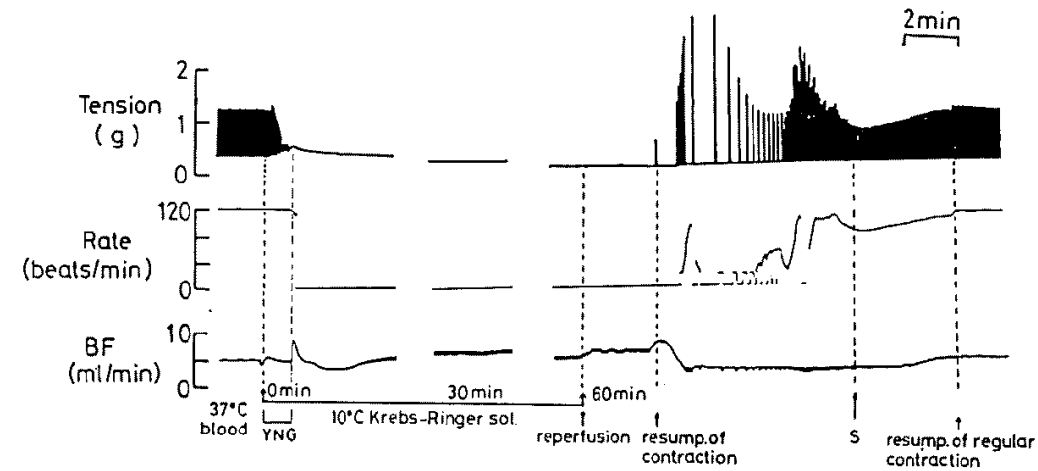

Fig. 8. Effects of cold YNG solution on the blood-perfused canine papillary muscle preparation. S: Withdrawal of the blood sample for measurement of oxygen consumption at $10 \mathrm{~min}$ blood reperfusion.

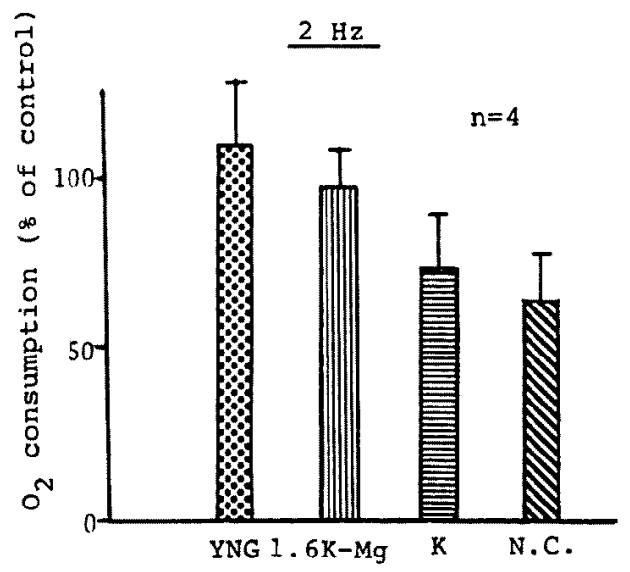

Control (ml/min/loog)

YNG $0.39 \pm 0.07$

$1.6 \mathrm{~K}-\mathrm{Mg} \quad 0.46 \pm 0.10$

K $\quad 0.49 \pm 0.13$

N.C. $0.33 \pm 0.10$

Fig. 9. Effects of cardioplegic solutions and cold cardioplegia on the oxygen consumption at $10 \mathrm{~min}$ after blood reperfusion. 
tion of regular contractions. Fig. 8 shows a representative time course of recovery after blood reperfusion of the contractile tension, the beating rate and the blood flow of the papillary muscle. The control value of the oxygen consumption of the papillary muscle was about 0.3 to $0.5 \mathrm{ml} / \mathrm{min} / 100 \mathrm{Gm}$. During of pacing at $2 \mathrm{~Hz}$, the oxgen consumption of the preparation arrested with YNG solution was restored almost to the control value $10 \mathrm{~min}$ after blood reperfusion ( $\mathrm{S}$ in Fig. 8), while it did not recover with other solutions. It was about $60 \%$ of the control value with the cold cardioplegia (Fig. 9).

\section{Discussion}

According to Young et al, ${ }^{3}$ the ideal cardioplegic solution must satisfy the following criteria: a quick and complete cardiac arrest, minimum metabolic effect, a quick resumption of the normal cardiac function and minimum damage to the myocardium or other structures. In our experiments with the papillary muscle preparation, the time to the cardiac arrest and the time to the maximum blood flow were significantly shorter with cardioplegic solutions under both conditions of automaticity and pacing at $2 \mathrm{~Hz}$ as compared with the cold cardioplegia, indicating the necessity of using a cardioplegic solution for protection of the myocardium. The maximum blood flow under pacing at $2 \mathrm{~Hz}$ showed a tendency to be greater with all cardioplegic solutions $(1.6 \%$ $\mathrm{K}^{+}-\mathrm{Mg}^{++}$solution $>\mathrm{YNG}$ solution $>\mathrm{K}^{+}$solution). On the other hand, the time to resumption of regular contractions was significantly shorter with YNG solution as compared with cold cardioplegia. The tension development and the blood flow at the time of resumption of regular contractions tended to approach the control value more quickly with YNG solution. The beneficial effects may be ascribed to the quick depolarization and resultant quick diastolic arrest produced by potassium, which preserves high-energy phosphate compounds (Levinsky et $\mathrm{al}^{10)}$ and Behrendt et $\mathrm{al}^{111}$ ) and provides better irrigation and quicker cooling of the myocardium. ${ }^{11)}$ However, our results show that the inclusion of magnesium in the solution provides for a more rapid recovery. However, the $1.6 \% \mathrm{~K}^{+}-\mathrm{Mg}^{++}$solution caused a quicker cardiac arrest, but a slower recovery of cardiac function as compared with YNG solution $\left(0.8 \mathrm{~K}^{+}-\mathrm{Mg}^{++}\right)$. Tyers et $\mathrm{al}^{6}$ ) also reported that the high potassium $\left(2.88 \% \mathrm{~K}^{+}\right)$cardioplegic solution of Melrose et $\mathrm{al}^{2)}$ resulted in a lower incidence of recovery. The better recovery may be a consequence of the inhibitory actions of magnesium ions on cardiac metabolism. The attainment of the control value of the oxygen consumption $10 \mathrm{~min}$ after blood reperfusion, observed in the preparation arrested with YNG solution, may be taken as another sign of the recovery of cardiac function. 
In the present study the time to resumption of regular contractions was different when tested under the condition of automaticity and pacing at $2 \mathrm{~Hz}$, suggesting that the resumption of automaticity does not necessarily mean the resumption of contractility. It seems that the cardioplegic solutions can produce a better preservation of the contractility than of automaticity.

\section{References}

1. Lam CR, Geoghegan T, Lepore A: Induced cardiac arrest for intracardiac surgical procedures. J Thorac Surg 30:620, 1955

2. Melrose DG, Dreyer B, Bentall HH, Baker JBE: Elective cardiac arrest. Lancet 2: 21 , 1955

3. Young WG Jr, Sealy WG, Brown IW Jr, Hewitt WC Jr, Callaway HA Jr, Merrit DH, Harris JS: A method for controlled cardiac arrest as an adjunct to open heart surgery. J Thorac Surg 32: 604,1956

4. Shumway NE, Lower RR: Topical cardiac hypothermia for extended periods of anoxic arrest. Surg Forum 10: 563, 1959

5. Mundth ED, Sokol DM, Levine FH, Austen WG: Evaluation of methods for myocardial protection during extended periods of aortic cross-clamping and hypoxic cardiac arrest. Bull Soc Int Chir 4: 227, 1970

6. Tyers GFO, Hughes HCJ Jr, Todd GJ, Williams DR, Andrew EJ, Prophet GA, Waldhausen JA: Protection from ischemic cardiac arrest by coronary perfusion with cold Ringer's lactate solution. J Thorac Cardiovasc Surg 67: 411, 1974

7. Stemmer EA, McCart P, Stanton WW, Thibault W, Dearden LS, Collolly JE: Functional and structural alterations in the myocardium during aortic cross-clamping. J Thorac Cardiovasc Surg 66: 754,1973

8. Wada J, Natsuaki M, Nakae S, Nagara H, Oteki H, Kato M, Kitamura N, Hashimoto A: Clinical evaluation for the effects of cold cardioplegic solution on myocardial protection. Effects of combined use of Young's solution and GIK solution. J Jpn Assoc Thorac Surg 28: 1099,1980

9. Endoh M, Hashimoto K: Pharmacological evidence of autonomic nerve activities in canine papillary muscle. Am J Physiol 218: 1459, 1970

10. Levinsky S, Merchant FJ, Feinberg H: Effects of KCl-induced cardiac arrest on energy metabolism and contractility of ischemic dog heart. Fed Proc 33: 398, 1974

11. Behrendt DM, Jochim KE: Effect of temperature of cardioplegic solution. J Thorac Cardiovasc Surg 76: 353, 1978 